\title{
Care Coordination for Children with Medical Complexity: Whose Care Is It, Anyway?
}

\author{
Dennis Z. Kuo, MD, MHS ${ }^{1}$ \\ Jeanne W. McAllister, BSN, MS, MHA ${ }^{2}$ \\ Lisa Rossignol, $\mathrm{MA}^{3}$ \\ Renee M. Turchi, MD, MPH ${ }^{4}$ \\ Christopher J. Stille, MD, MPH
}

\author{
${ }^{1}$ University at Buffalo School of Medicine, Buffalo, NY \\ ${ }^{2}$ Indiana University School of Medicine, Indianapolis, IN \\ ${ }^{3}$ New Mexico Disability Story, Albuquerque, NM \\ ${ }^{4}$ St. Christopher's Hospital for Children and Drexel University School of Public Health, \\ Philadelphia, PA \\ ${ }^{5}$ University of Colorado School of Medicine, Denver, CO
}

Address correspondence to: Dennis Kuo, UBMD Pediatrics, Hodge Pediatrics, 125 Hodge Ave, Buffalo, NY 14222, dkuo@upa.chob.edu, 716-878-7277.

Short Title: Care Coordination for Children with Medical Complexity

Word Count: 4,054

Funding Source: This publication was made possible by the Lucile Packard Foundation for Children's Health.

Financial Disclosures: The authors have no financial relationships that are relevant to this article to disclose.

Conflict of Interest: The authors have no conflicts of interest to disclose.

\begin{abstract}
Abbreviations: $\mathrm{CMC}-$ Children with Medical Complexity
Table of Contents Summary: This review of care coordination for children with medical complexity addresses infrastructure, implementation, care coordination tools, and appropriate resource allocation under new payment models.
\end{abstract}

What's Known on this Subject: Children with medical complexity require an array of medical and community-based providers. Dedicated care coordination can address the fragmented care that $\mathrm{CMC}$ often encounter but care coordination is often conceptually misunderstood.

What This Manuscript Adds: Care coordination is a team-driven activity that organizes and drives service integration in family partnership. Infrastructure building, design and implementation leadership, tools and training modules, and resource allocation under new payment models are needed for adequate care coordination for CMC. 


\section{Contributors' Statements}

Dennis Z. Kuo, MD, MHS: Dr. Kuo conceptualized and designed the manuscript, drafted the initial manuscript, and approved the final manuscript as written.

Jeanne W. McAllister, BSN, MS, MHA: Ms. McAllister analyzed and interpreted the study data, revised the manuscript for important intellectual content, and approved the final manuscript as written.

Lisa Rossignol, MA: Ms. Rossignol analyzed and interpreted the manuscript data, revised the manuscript for important intellectual content, and approved the final manuscript as written.

Renee M. Turchi, MD, MPH: Dr. Turchi analyzed and interpreted the manuscript data, revised the manuscript for important intellectual content, and approved the final manuscript as written.

Christopher J. Stille, MD, MPH: Dr. Stille conceptualized and designed the manuscript, revised the manuscript for important intellectual content, and approved the final manuscript as written.

All authors approved the final manuscript as submitted and agree to be accountable for all aspects of the work. 


\begin{abstract}
Children with medical complexity have multiple chronic conditions and require an array of medical and community-based providers. Dedicated care coordination is increasingly seen as key to addressing the fragmented care that $\mathrm{CMC}$ often encounter. Often conceptually misunderstood, care coordination is a team-driven activity that organizes and drives service integration. In this paper we examine models of care coordination and clarify related terms such as care integration and case management. The location of care coordination resources for CMC may range from direct practice provision to external organizations such as hospitals and accountable care organization. We discuss the need for infrastructure building, design and implementation leadership, use of care coordination tools and training modules, and appropriate resource allocation under new payment models.
\end{abstract}




\section{Introduction}

One in five American families have a child or youth with special health care needs (CYSHCN), defined as a child who has medical care needs beyond those of typical children. ${ }^{1,2}$ Children with medical complexity (CMC) are a subset of this group: those who have multiple chronic conditions that often require the care of an array of community- and hospital-based providers ${ }^{3}$. The current fragmentation of existing health care systems frequently makes it difficult for families of CMC to get the services they need. Depending on the severity of the child's illness or condition, families can spend considerable time communicating among providers and across systems, assimilating recommendations, coordinating appointments, addressing insurance and financial issues, or performing therapeutic activities. ${ }^{4}$ In addition, families often have to juggle these tasks while caring for additional children in the household. High-quality services may be individually offered from multiple entities across systems, but integration and coordination of relationships between families and service providers is often lacking.

Care coordination is increasingly emerging as an "answer" to health care and community system fragmentation. In recent years, the Affordable Care Act (ACA) has encouraged and incentivized care coordination services to patients with higher levels of medical complexity. The ACA also encouraged the development of both highperforming primary care practices, also known as patient-centered medical homes $(\mathrm{PCMH})$, and accountable care organizations that would then provide care coordination services. $^{5,6}$ In pediatrics, the focus of care coordination is often directed towards CMC, due to their disproportionate use of multiple health care services required to maximize their potential. ${ }^{3}$ Outpatient care coordination, where the bulk of health care is delivered, 
improves quality of care and health outcomes, through proactive care planning, more efficient use of resources and prevention of unnecessary health care encounters. ${ }^{7}$ Implementation of care coordination, particularly for $\mathrm{CMC}$, remains challenging due to personnel training needs, staffing requirements, varying levels of family engagement, scope of care coordination duties, payment/sustainability, and care models that are largely adult focused.

This paper represents a group effort of physicians, family advocates, and health policy experts. We define optimal care coordination, care planning and care integration and discuss their intersection with other concepts such as case management and care management. We discuss best practices and provide an overview of the implementation process to achieve the most optimal outcomes and values for CMC. Finally, we review payment models emerging to support the concepts of care coordination and planning for CMC.

\section{Definitions and Terms}

Care coordination is a broadly attractive concept meaning very different things to different providers, consumers and payers, and many different activities are often performed under the umbrella of care coordination. Definitions of care coordination have been derived from varied sources, including families requesting help with unmet needs, payer attempts to allocate scarce resources, health care organizations streamlining care within their own systems, and community organizations working to meet patient and family needs within the constraints of regulatory and payer systems. It is important to clarify the concept of care coordination and distinguish it from related concepts like care integration and case management. 
Antonelli, McAllister and Popp in 2009 published a framework outlining the definition and scope of care coordination, ${ }^{8}$ which was reiterated in the current policy statement by the American Academy of Pediatrics. ${ }^{9}$ The framework defines care coordination as "a patient and family-centered, assessment-driven, team-based activity designed to meet the needs of children and youth while enhancing the care giving capabilities of families. Care coordination addresses interrelated medical, social, developmental, behavioral, educational and financial needs to achieve optimal health and wellness outcomes." Four defining characteristics of care coordination are provided: 1) family-centeredness; 2) planned, proactive and comprehensive focus; 3) promotion of self-care skills and independence, and 4) emphasis on cross-organizational relationships.

Several aspects of the Antonelli framework merit further discussion. First, care coordination should incorporate the perspective of the family and center around their goals, but the degree to which care coordination is operationalized to be family-centered varies by program, practice, agency, and/or system. For example, some care coordination programs may focus on access and adherence to specialty appointments or therapies but may not address the needs of patients and families outside the medical care sector. Second, assessments of service needs may be formal, structured, or informal, but are best integrated into routine care delivery as standard practice. Third, "team-based" care coordination emphasizes the importance of multiple roles in care coordination, including parents/caregivers, primary care providers, and their team that ideally includes a designated care coordinator, specialists, educators, pharmacists, mental health providers, therapeutic support services and others. Finally, optimal care coordination needs to 
recognize and address psychosocial determinants of health and their contribution to optimal health and wellness.

The difference between care coordination and a related term, care integration, warrants discussion. Broadly, care coordination can be thought of as the activities that produce or foster care integration. Care coordination refers specifically to the activities occurring across primary care and specialty visits, hospital admissions, and accessing community resources. In contrast, care integration is the result of effective coordination: "the seamless provision of health care services, from the perspective of the patient and family, across the entire care continuum. It results from coordinating the efforts of all providers, irrespective of institutional, departmental, or community-based organizational boundaries." ${ }^{10}$ Care integration is easiest to achieve when patients and families are fully engaged in care and negotiating goals and priorities together, and when collaborative care models (such as mental health integration) are readily available for patients and families. Care coordination, by providing communication and support between visits and addressing social determinants of health, is necessary (but not always sufficient) to achieve full care integration of health care services for patients and families.

Case management is often used interchangeably with care coordination, but conceptually may have a narrower focus. Case management has frequently been operationalized as management of a specific disease process or condition and treatment such as diabetes, cancer, or cerebral palsy, often focusing on allocation of limited resources for a specific patient. ${ }^{11}$ Case management services may be located in an inpatient setting, private practice, ambulatory setting, within managed care organizations, Title V programs or in specialty clinics such as nephrology or endocrinology. Case 
managers often allocate resources intrinsic to their specific agency within the parameters of eligibility critieria. ${ }^{10}$ These positions have some variance of professional qualifications but they tend to be social workers or registered nurses (RNs ) with specialized skills and knowledge specific to the populations they serve. ${ }^{12}$

Care management has been described as a team-based, patient centered, systemlevel approach to populations, "designed to assist patients and their support systems in managing medical conditions more effectively." ${ }^{\prime 3}$ Care management encompasses identification of at-risk populations, alignment of appropriate services, and training of specific providers, with the aim of alleviating the negative effects of care fragmentation. ${ }^{13,14}$ Some health care initiatives apply combinations of care management and care coordination activities as population- and patient-level activities. ${ }^{14}$ The Antonelli/AAP frameworks of care coordination highlight provider/family partnership, combined with a team process critical for highly-functioning care delivery across medical, education, payment, and other systems; these elements are drivers of health for the child and family and frequently encompass social determinants of health. Thus, we believe that this broad definition of care coordination is functionally similar to "care management", particularly in its direct support of family functioning and activities that are external of direct service access or specific disease processes. A key difference is the application of care coordination with and for individual patients, with care coordination being a specific activity that may reside within a care management strategy for populations. We would like to caution all participants in the healthcare community to be thoughtful in using appropriate terms for each function and advocate discarding emerging 
terms that further complicate understanding of systems of care for patients, families and providers.

Finally, care mapping can be a useful approach to elucidate why quality care coordination is needed for CMC. At the level of the individual patient, care mapping is a visual detailed account of patient and family needs and strengths, and demonstrates the interactive relationships among the various team members and resources at both the micro and macrosystem level. ${ }^{15}$ A care map portrays the family in the center of the multiple people, processes, interventions, organizations, and methods by which communication and interventions must occur. [Figure 1] ${ }^{16}$ Training providers and families in care mapping can be a valuable exercise to actively engage families and activate teams.

\section{Infrastructure for care coordination and planning}

Effective care coordination and care planning for $\mathrm{CMC}$ may occur in a number of settings, including the primary care practice, the tertiary care center, or an organization external to the practice setting such as community agencies. Regardless of the setting, care coordination activities are supported by adequate staffing, assessment tools, information technology (IT), and training with infrastructure supportive of family/provider collaborative partnerships. This requires leadership, adequate planning and time for structured, studied implementation. Planning for care coordination at the organization level needs to be methodical and inclusive, utilizing available tools and being incorporated within an integrated work flow design. ${ }^{17}$ A key first step includes an assessment at the level of the primary care practice, the team, or other clinical microsystem, ideally formal, of both the needs of the priority population (including 
patients and families $)^{18}$ and the practice/clinical setting. Patients and families should be engaged as partners at all levels of organization and decision making, including goal setting, care planning with use, and assessing their care integration experience. ${ }^{9,19}$ Assessment of the capabilities of the practice team is also integral to successful care planning to target areas for quality improvement and practice transformation. Measurements of specific capabilities can quantify efforts such as coordination within and between care teams, communication between primary care/specialty care or community partners, needed staff time/resources and potential benefits to patients and the practice context. ${ }^{20,21}$

Staffing and necessary training with continuous learning may be influenced by the local payment environment, including services supported by payers, and available resources including care coordinators who may be external to the practice and/or the clinical microsystem. The evolving health care marketplace and population health approach to care delivery warrants special consideration. ${ }^{22,23}$ Practices and health care systems may choose to train their own internal teams and staff, work/hire community based care coordination teams or agencies, contract with health care systems or engage with children's hospitals for the provision of care coordination integration services. ${ }^{24}$ Engaging community partners may promote efficiency by enabling resource pooling or sharing care coordination positions across settings/practices that perhaps could not be afforded otherwise.

A highly performing care team, with engagement of patients, families and community partners in all phases, is paramount for successful care planning as part of the larger care coordination process. ${ }^{25}$ Such care team members include clinical and 
nonclinical professionals as well as family members, with specific, defined roles and dedicated time and effort specific to care planning. ${ }^{26}$ Staff roles and contributions should be defined and understood by all members. ${ }^{27}$ Ensuring that team members work to the "top of their license" fosters cost effectiveness and efficiency. For example, measuring team activities may reveal that a nurse is spending hours per day faxing orders and prescriptions, precluding his/her ability to provide higher levels of care coordination and clinical care. Key community resources external to the organization, such as mental health agencies, schools, equipment providers, and home nursing services are important to collaborate with as well.

Implementation requires modeling of care coordination competencies and functions while detailing specific processes. ${ }^{8,28}$ Existing tools for care coordination activities, select models supported by a staff training curriculum, an implementation design process map, and a biopsychosocial patient/family assessment can standardize processes. A flexible and modifiable care coordination curriculum ${ }^{16}$ exists to train health care teams to develop competencies such as care planning, integration with behavioral health, and safe transitions of care (transition from inpatient to outpatient and to the adult sector). ${ }^{9}$ Developing patient registries for disease and population management, utilizing team huddles, ${ }^{29}$ scheduling regular team meetings with role definitions, leveraging health information systems and technology, and applying measurement tools are key activities. ${ }^{30}$

Care coordination and care planning for $\mathrm{CMC}$ requires tailoring resources to children's needs, based on assessments by a team member who is broadly familiar with the child and family. Health information/data exchanges as well as interoperable electronic health records can assist with identification of needs and facilitate care 
coordination communication when accessible. The advent of electronic health records can afford real-time access to updated plans of care, including on smart phones and tablets. Patient portals may afford opportunities for health care teams to share aspects of the health care record with patients and families including care plans after their visit encounter in virtually any location if they have access to the internet. ${ }^{31,32}$ Families can still be given paper copies of plans of care as well as other tools to promote their roles as active team members.

\section{Implementation}

Implementation of care coordination and care planning can be complex due to the multiple components of care that $\mathrm{CMC}$ need and or experience. Care coordination may create - rather than solve - problems if/when multiple well-meaning care coordinators act independently. The concept of relational coordination ${ }^{33}$ was originally framed to describe communication and collaboration among defined roles within the airline industry. Relational coordination emphasizes shared goals and knowledge, timely communication, and mutual respect among all care-giving members including the family. The relational coordination concept is useful to consider where complex systems must function consistently and reliably at all times. Health care systems with their inherent cultures often fail to demonstrate these cross-organizational principles. ${ }^{34}$ Organizational emphasis on shared goals, timely communication, and mutual respect as driving principles can improve patient care and positively impact the implementation of care coordination for CMC.

A major challenge to implementation of care coordination can be a lack of coordination among multiple coordinating efforts targeting different types of services that 
a child needs. A promising practice is having a designated lead or locus of coordination, preferably within the child's medical home, when medical complexity is recognized. For CMC, the most useful function of such high-level care coordination shifts from coordinating distinct activities and tasks to coordinating across the multiple health and service providers who perform these activities. This approach is in line with the concept of relational coordination, where shared goals and knowledge, timely communication and mutual respect are paramount. ${ }^{33}$ For $\mathrm{CMC}$, additional consideration may be given to multidisciplinary training that enables navigation through different medical, mental health, and social service spheres.

Care coordination works best with a partnership approach that emphasizes growth, development and wellness. Families can best articulate the strengths of their child and family and the challenges faced, and identify and prioritize their particular care coordination needs. Structured assessments, including semi-structured conversations or interviews, help all to understand what matters most to families, but these are often not well utilized by health care systems.

Care coordination may facilitate a care planning process using an explicit workflow and supportive tools. The recent report "Achieving a Shared Plan of Care with Children and Families with Special Health Care Needs"17 describes processes by which health care teams and families develop a shared, written plan of care, carried out with the support of a high-level, team-based care coordinator. The shared plan of care is created when the coordinating team and family blend medical summary data with negotiated actions - specifically family goals and team concerns - merging them into a strategic plan 
of actions to use and follow. The shared plan of care outlines and guides subsequent care coordination activities to be achieved in partnership with families over time.

Insufficient understanding and experience remain about optimal implementation of care coordination. Available time remains a key factor, particularly for primary care and specialty providers alike who largely remain tied to volume-driven payments. Practice transformation - systematic changes in organization and processes within the primary care-based medical home - supports team-based care and staffing models that are not tied to service volume, and thus may be foundational for effective care coordination and care planning. Components of practice transformation include defined patient panels for each clinician, team-based care, ${ }^{35}$ family partnerships, and continuous quality improvement processes. ${ }^{36,37}$ Berry and colleagues have called for studies to identify best practices and dissemination of care coordination implementation. ${ }^{38}$ Data from such studies, informed strongly by family input as research and clinical partners, may help inform the selection of a small number of refined approaches that may be scaled up quickly. Development, testing, and stabilization of quality care coordination is taking center stage within health system transformation efforts. ${ }^{39}$ Implementation and sustainability of these efforts will require robust evaluation and subsequent refinement, using continuous quality improvement methodology, to promote the integration of evidence into healthcare policy and practice. ${ }^{40}$

Care coordination needs of CMC evolve over time. For example, an infant with intractable epilepsy may initially attend multiple neurology and primary care appointments and receive early intervention services at home. Intermittent hospitalizations may involve more specialists and medications and subsequently a 
corrective surgery which creates global functioning deficits, requiring additional detailed care integration with transition from hospital to home. Transition to public school from early intervention programs requires initiation of school-based therapies and outpatient rehabilitation adding additional layers of formalized services. Further growth and emerging adolescence may require endocrine, orthopedic surgery, home nursing services, mental health services and planning for transition to the adult health care system. Care coordination with $\mathrm{CMC}$ requires structured clarity while also being flexible, adaptive, and capable of addressing the lived experiences of the child and family through changing spheres; the psychosocial determinants of health particularly add to the complexity of care. $^{41}$

\section{Payment}

Payment for care coordination and planning should support, at a minimum, personnel time for teamwork and communication. Historically, care coordination in the primary care setting has not been adequately financed in most payer models. In the traditional fee-for-service system, payments reward in-person encounters and face-to-face time, with higher payments linked to billing codes that may reflect diagnostic complexity, management complexity, and time spent. In contrast, care coordination activities may often be delivered without the patient and family being physically present. Care management fees, linked to appropriate billing codes, are designed to address non-faceto-face time that characterizes care coordination. Care management fees may be linked to reported time spent on the non-face-to-face time, but payment for other billing codes such as care plan oversight is variable and often underutilized. 
Primary care remains largely tied to volume-driven payments that do not adequately support non-face-to-face time during which many care coordination activities occur. Recent movement towards alternative payment models (e.g. value based payments, population health, bundled per member per month models) offers opportunities to redefine how care coordination and planning are supported for CMC. ${ }^{42}$ Alternative models provide payments that, instead of rewarding numerous in-person encounters, are linked to patient panel size, quality metrics, or shared savings, incentivizing preventive and proactive health care planning. Payments may be provided independent of an inperson encounter, and are provided depending upon the amount of time a patient is assigned to a panel, e.g. "per member per month". De-coupling of payments from inperson encounters provides flexibility in how revenue is applied towards personnel time as well as office overhead for personnel. Such payments, if sufficient to truly enable change, may be applied to support care coordination activities in clinical practices, with the intent to reduce undesired, preventable encounters linked with high cost. ${ }^{6}$ Risk stratification with acceptance of financial risk for CMC may further support dedicated care coordination services at the accountable care organization level. ${ }^{43}$

The amount of payment necessary to support care coordination and planning for $\mathrm{CMC}$, with a return on investment for high resource utilizers, is unknown. The adequacy of payments linked to quality metrics, value based healthcare or panel sizes depend on accurate predictions of overhead costs and projected appropriate resource usage. ${ }^{44}$ Appropriate risk stratification can identify children who have higher levels of medical and/or social complexity and accompanying need for more intensive support services. Predictive algorithms used by payers are often based on billing claims history. Billing 
claims may be insufficient to accurately describe care complexity, social determinants of health, and future health care needs. ${ }^{45}$ It is imperative that payers work with providers to construct appropriate payment models with adequate levels of financial support to maintain, support, and evaluate care coordination services.

A fully capitated, at-risk payment model is often considered the final step in payment transformation, ${ }^{46}$ as payments are linked directly to population numbers and not service volume. The payment model requires the creation of large patient networks that are able to spread financial risk among multiple providers. A payer with a large patient and panel network may also opt to employ its own care coordination services located external to individual practices, either within the payer organization or under a contract with a separate agency. In such cases the care coordination services may be provided free of charge to the provider and family. The challenge reverts to relational coordination, particularly adequate integration of care coordination and care planning with families, and among primary care, specialty care, and community partners (the care map).

\section{Culture change}

Health care delivery has traditionally focused on biological approaches to ameliorating illness, rather than addressing the social determinants of health and optimal functioning in the context of one's community ${ }^{47}$ Similarly, the scope of care coordination as seen by its participants - families, coordinators, and service providers varies widely across populations. Coordinators historically focusing on case management may define their duties as narrowly related to management of a specific health condition. 
Others may have worked in an environment with a social service focus where community service coordination has been emphasized over more technical coordination and management of equipment and services. Comparatively few programs document experiences spanning the full spectrum of care coordination with ongoing learning, reassessment and adjustments characteristic of implementation science. Families and clinicians report a range of care experiences with designated care coordinators as part of their work. ${ }^{9,19,48}$

A comprehensive approach to care coordination requires a cultural shift to embrace the full spectrum of health and its determinants, including social determinants of health. Such a shift may encompass structured routine screening and referral for social determinants, care coordinator training that extends across the medical and social service sectors, and collaborative care planning that may encompass finances, employment, housing, food security, transportation, and other social determinants. Highly competent care coordination, with fidelity to a best practice definition, embraces such culture change in order to ensure a common understanding and adequate care planning among patients, families, care coordinators and care providers, and payers. Education about strengths of and resources available to each team member, followed by detailed integration of tasks into shared plans of care, may lead to relational coordination potentially producing efficient, effective resource use while meeting family needs. Very little has been published $^{38}$ about implementation of these processes, but this knowledge is critical to help practices, care coordination entities, and payers design comprehensive learning systems of care coordination for CMC.

\section{Conclusions}


Children with medical complexity often experience fragmented care. Care coordination is a team-driven activity that is foundational to foster care integration, the desired outcome for CMC. Care coordination is fundamentally patient- and familycentered and requires a partnership approach that supports proactive planning of care and encompasses social determinants of health. Infrastructure capacity building, design and implementation leadership, use of tools and training modules, and appropriate resource allocation among populations are foundational for success. Payment reform models may increasingly support authentic care coordination activities, with its locus of implementation ranging from direct provision in the primary care setting, to specialty practices, to external organizations such as hospitals and accountable care organizations. Effective relational coordination among multiple entities is essential for optimal outcomes for CMC.

$\mathrm{CMC}$ are increasingly being identified as a priority population under population health -based strategies and thus may merit dedicated care coordination efforts. ${ }^{42}$ Leadership entities will need to understand the components of care coordination, the relationships among its components, and underlying infrastructure needs such as practice transformation and available tools and assessments. Care mapping can elucidate the dozens of care components concurrently impacting the health of the child and family. A patient- and family-centered focus enables care coordination to develop holistic care processes, emphasize family-centered goals and partnership, and support selfmanagement while integrating care components. Optimally designed and delivered, care coordination for $\mathrm{CMC}$ provides the infrastructure (or capacity) and the tools to support effective, integrated care for $\mathrm{CMC}$ and their families. 
References

1. US Department of Human Services, Health Resources and Services Administration, Maternal and Child Health Bureau. Child Health USA 2014. Rockville, MD: US Department of Health and Human Services;2014.

2. McPherson M, Arango P, Fox H, et al. A new definition of children with special health care needs. Pediatrics. 1998;102(1 Pt 1):137-140.

3. Cohen E, Kuo DZ, Agrawal R, et al. Children with medical complexity: An emerging population for clinical and research initiatives. Pediatrics. 2011;127(3):529-538.

4. Kuo DZ, Cohen E, Agrawal R, Berry JG, Casey PH. A National Profile of Caregiver Challenges Among More Medically Complex Children with Special Health Care Needs. Arch Pediatr Adolesc Med. 2011;165(6):1020-1026.

5. Fry-Bowers EK, Nicholas W, Halfon N. Children's Health Care and the Patient Protection and Affordable Care Act: What's at Stake? JAMA pediatrics. 2014;168(6):505-506.

6. Edwards ST, Abrams MK, Baron RJ, et al. Structuring Payment to Medical Homes After the Affordable Care Act. J Gen Intern Med. 2014;29(10):14101413.

7. Berry JG, Hall M, Neff J, et al. Children with medical complexity and medicaid: spending and cost savings. Health Aff (Millwood). 2014;33(12):2199-2206.

8. Antonelli RC, McAllister JW, Popp J. Making Care Coordination a Critical Component of the Pediatric Health System: A Multidisciplinary Framework. New York: The Commonwealth Fund;2009.

9. Council On Children With Disabilities, Medical Home Implementation Project Advisory, American Academy of Pediatrics. Patient- and Family-Centered Care Coordination: A Framework for Integrating Care for Children and Youth Across Multiple Systems. Pediatrics. 2014;133(5):e1451-1460.

10. Antonelli R. Achieving HIgh Value Outcomes: Using Measurement to Drive System Performance Measurement for Children and Youth With Special Health Care Needs. 2015; https://www.nga.org/files/live/sites/NGA/files/pdf/2015/1511LearningCollaborati veAntonelli.pdf. Accessed November 13, 2016.

11. Taylor EF, Machta RM, Meyers DS, Genevro J, Peikes DN. Enhancing the primary care team to provide redesigned care: the roles of practice facilitators and care managers. Ann Fam Med. 2013;11(1):80-83.

12. Watson AC. Finding common ground in case management: new titles and terminology along the health care continuum. Prof Case Manag. 2011;16(2):5254.

13. Center for Health Care Strategics Ind. Care Management Definition and Framework. Trenton, NJ, 2007.

14. Agency for Healthcare Research and Quality. Care Management: Implications for Medical Practice, Health Policy, and Health Services Research. Rockville, MD: Agency for Healthcare Research and Quality; April 2015. 
15. Golden SL, Nageswaran S. Caregiver voices: coordinating care for children with complex chronic conditions. Clin Pediatr (Phila). 2012;51(8):723-729.

16. Boston Children's Hospital. Care Coordination Curriculum. 2013. http://www.childrenshospital.org/care-coordination-curriculum. Accessed 8/14/2017.

17. McAllister J. Achieving a Shared Plan of Care with Children and Youth with Special Health Care Needs. Palo Alto, CA: Lucile Packard Foundation for Children's Health; May 2014.

18. Walker KO, Stewart AL, Grumbach K. Development of a survey instrument to measure patient experience of integrated care. BMC Health Serv Res. 2016;16:193.

19. Cene CW, Johnson BH, Wells N, Baker B, Davis R, Turchi R. A Narrative Review of Patient and Family Engagement: The "Foundation" of the Medical "Home". Med Care. 2016;54(7):697-705.

20. Ferrari LR, Ziniel SI, Antonelli RC. Perioperative Care Coordination Measurement: A Tool to Support Care Integration of Pediatric Surgical Patients. A A Case Rep. 2016;6(5):130-136.

21. McDonald KM, Schultz E, Albin L, et al. Care Coordination Atlas Version 4 (Prepared by Stanford University under subcontract to American Institutes for Research on Contract No. HHSA290-2010-000051). Rockville, MD: Agency for Healthcare Research and Quality; June 2014.

22. National Quality Forum. Preferred Practices and Performance Measures for Measuring and Reporting Care Coordination: A Consensus Report. Washington, D.C.: NQF;2010.

23. Henderson M, Kaye N. Policies for Care Coordination Across Systems: Lessons from ABCD III. Portland, ME: National Academy for State Health Policy; May 2012.

24. Farmer JE, Clark MJ, Drewel EH, Swenson TM, Ge B. Consultative care coordination through the medical home for CSHCN: a randomized controlled trial. Matern Child Health J. 2011;15(7):1110-1118.

25. American Academy of Pediatrics. Parent-Provider-Community Partnerships: Optimizing Outcomes for Children With Disabilities. Pediatrics. 2011;128(4):795-802.

26. Solimeo SL, Stewart GL, Rosenthal GE. The Critical Role of Clerks in the Patient-Centered Medical Home. Ann Fam Med. 2016;14(4):377-379.

27. Phillips J, Hebish LJ, Mann S, Ching JM, Blackmore CC. Engaging Frontline Leaders and Staff in Real-Time Improvement. Joint Commission journal on quality and patient safety / Joint Commission Resources. 2016;42(4):170-183.

28. Helfrich CD, Sylling PW, Gale RC, et al. The facilitators and barriers associated with implementation of a patient-centered medical home in VHA. Implementation science : IS. 2016;11:24.

29. Chen EH, Thom DH, Hessler DM, et al. Using the Teamlet Model to improve chronic care in an academic primary care practice. J Gen Intern Med. 2010;25 Suppl 4:S610-614. 
30. Rodriguez HP, Meredith LS, Hamilton AB, Yano EM, Rubenstein LV. Huddle up!: The adoption and use of structured team communication for VA medical home implementation. Health Care Manage Rev. 2015;40(4):286-299.

31. Ancker JS, Barron Y, Rockoff ML, et al. Use of an electronic patient portal among disadvantaged populations. J Gen Intern Med. 2011;26(10):1117-1123.

32. Goel MS, Brown TL, Williams A, Cooper AJ, Hasnain-Wynia R, Baker DW. Patient reported barriers to enrolling in a patient portal. $J$ Am Med Inform Assoc. 2011;18 Suppl 1:i8-12.

33. Gittell JH, Seidner R, Wimbush J. A Relational Model of How High-Performance Work Systems Work. Organization Science. 2010;21(2):490-506.

34. Gittell JH. High Performance Healthcare: Using the Power of Relationships to Achieve Quality, Efficiency, and Resilience. 2009.

35. Katkin JP, Kressly SJ, Edwards AR, et al. Guiding Principles for Team-Based Pediatric Care. Pediatrics. 2017;140(2):e20171489.

36. Wagner EH, Gupta R, Coleman K. Practice transformation in the safety net medical home initiative: a qualitative look. Med Care. 2014;52 Suppl 4:S18-22.

37. McAllister JW, Cooley WC, Van Cleave J, Boudreau AA, Kuhlthau K. Medical home transformation in pediatric primary care--what drives change? Ann Fam Med. 2013;11 Suppl 1:S90-98.

38. Berry J. What children with medical complexity, their families and healthcare providers deserve from an ideal healthcare system. Palo Alto, CA: Lucile Packard Foundation for Children's Healthcare;2015.

39. Children's Hospital Association CARE Award. 2017; https://www.childrenshospitals.org/careaward. Accessed August 14, 2017.

40. Damschroder LJ, Aron DC, Keith RE, Kirsh SR, Alexander JA, Lowery JC. Fostering implementation of health services research findings into practice: a consolidated framework for advancing implementation science. Implementation science : IS. 2009;4:50.

41. Kuo DZ, Houtrow AJ, Disabilities ACoCW. Recognition and Management of Medical Complexity. Pediatrics. 2016;138(6):e20163021.

42. Bachman SS, Comeau M, Long TF. Statement of the Problem: Health Reform, Value-Based Purchasing, Alternative Payment Strategies, and Children and Youth With Special Health Care Needs. Pediatrics. 2017;139(Suppl 2):S89-S98.

43. Weier RC, Gardner W, Conkol K, Pajer K, Kelleher KJ. Partners for Kids Care Coordination: Lessons From the Field. Pediatrics. 2017;139(Suppl 2):S109-S116.

44. Farmer SA, Shalowitz J, George M, et al. Fully Capitated Payment Breakeven Rate for a Mid-Size Pediatric Practice. Pediatrics. 2016;138(2).

45. Berry JG, Hall M, Cohen E, O'Neill M, Feudtner C. Ways to Identify Children with Medical Complexity and the Importance of Why. J Pediatr. 2015;167(2):229-237.

46. The Commonwealth Fund Commission on a High Performance Health System. The Path to a High Performance U.S. Health System: A 2020 Vision and the Policies to Pave the Way. New York, NY: The Commonwealth Fund; February 2009.

47. Trujillo MD, Plough A. Building a culture of health: A new framework and measures for health and health care in America. Soc Sci Med. 2016;165:206-213. 
48. Friedman A, Howard J, Shaw EK, Cohen DJ, Shahidi L, Ferrante JM. Facilitators and Barriers to Care Coordination in Patient-centered Medical Homes (PCMHs) from Coordinators' Perspectives. J Am Board Fam Med. 2016;29(1):90-101. 
Table 1. Definitions of common terms when describing care coordination and care planning for children with medical complexity.

\begin{tabular}{|l|l|l|}
\hline \multicolumn{1}{|c|}{ Term } & \multicolumn{1}{|c|}{ Target } & \multicolumn{1}{c|}{ Definition } \\
\hline $\begin{array}{l}\text { Care } \\
\text { coordination }\end{array}$ & $\begin{array}{l}\text { Patient/family (as } \\
\text { partners) }\end{array}$ & $\begin{array}{l}\text { Family-centered, assessment-driven, team-based } \\
\text { activity addressing comprehensive needs with } \\
\text { families }\end{array}$ \\
\hline $\begin{array}{l}\text { Care } \\
\text { integration }\end{array}$ & System & $\begin{array}{l}\text { Seamless provision of health care services across } \\
\text { the care continuum, the result of care coordination }\end{array}$ \\
\hline $\begin{array}{l}\text { Case } \\
\text { management }\end{array}$ & Disease & Management of specific disease or process \\
\hline $\begin{array}{l}\text { Care } \\
\text { management }\end{array}$ & System & $\begin{array}{l}\text { Organization of population level services, } \\
\text { including risk stratification, service allocation and } \\
\text { care coordination activities }\end{array}$ \\
\hline $\begin{array}{l}\text { Care } \\
\text { planning }\end{array}$ & Patient/family & $\begin{array}{l}\text { Strategic steps to take as a function of care } \\
\text { coordination, best co-produced and recorded in } \\
\text { writing }\end{array}$ \\
\hline $\begin{array}{l}\text { Care } \\
\text { mapping }\end{array}$ & Patient/family & $\begin{array}{l}\text { Visual, detailed account of patient and family } \\
\text { needs and strengths, demonstrating interactive } \\
\text { relationships among team members and resources } \\
\text { needed for effective, family-centered care for } \\
\text { CMC }\end{array}$ \\
\hline
\end{tabular}




\section{Figure 1 Legend.}

From the parent: "A care map for Lily at age 8. Notice that, in addition to being incredibly chaotic in appearance, there are some key areas that are 58 professionals or supporting relationships being managed by the parent in the care of a child with medical complexity.

One year later, those relationships have been reduced to 46 through careful consultation with the child's PCP and trusted providers. There were unnecessary redundancies in care that were never seen before and the care map created a clear roadmap to remove excess activities, bills, and obligations. Additionally, the parents resigned from many of the advocacy activities that did not directly appeal to their interests and focused on increasing leisure and recreation.

The child's condition didn't change at all, but the family was able to visualize and then build a more organized life for the entire family." 